\title{
Assessment of discharge and sediment flows in a river through a combined hydraulic and hydrologic routing techniques
}

\author{
Abebe Tadesse Bulti \\ Hawassa University, Institute of Technology, College of Biosystems and water resources, Department of Hydraulic \\ andWater Resources - address -abebulti@yahoo.com, Ethiopia \\ * Corresponding Author \\ Abebe Tadesse- abebulti@yahoo.com, abebetadesse@,hu.edu.et
}

\begin{abstract}
An advancement of flood routing methods is important for the design and management of the water resources systems. Hydraulic and hydrologic routing approach are widely applied in most simulation models, separately. The combined hydrologic and hydraulic routing method where recent approach to improve the modeling effort in hydrological studies. The main drawback of hydrologic routing methods was inaccuracy on downstream areas of the river basin, where the effect of hydraulic structures and the river dynamics processes are dominant. The hydraulic routing approaches are relatively good on a downstream reaches of a river. This research was done on the Awash River basin at the upstream areas of a Koka dam. A combined hydrologic and hydraulic approach was used to assess the discharge and sediment flow in the river basin. The hydrologic routing method was applied at an upstream part of a river basin through a SWAT model. HECRAS model was applied at the middle and downstream areas of the basin based on hydraulic routing principle. The combined routing method can improve the result from the simulation and increases the accuracy in the prediction of the peak flow. It can simulate all the discharges for both short and long-term duration with good model performance indicators. Besides, sediment modeling was done by comparing the regression model, SWAT model, and combination of HEC-
\end{abstract}


RAS and SWAT model. The result from the sediment modeling indicates that the regression model and the combined models show good agreement in predicting the suspended sediment in the Awash River basin.

Keyword: Hydrologic routing, Hydraulic routing, Flow discharge, Suspended sediment, Awash River 


\section{Introduction}

Flow routing is important to estimate the propagation of flood from upstream to the downstream reach of a river, lakes, and reservoirs. The actual propagation of flow is a complicated process and it involves an advanced modeling approach. The process tends to hydraulic rather than hydrologic process. However, currently, most hydrologic and hydraulic models are applied for the flow routing in river basins with certain simplifications. The routing methods are used to estimate both flood prediction and forecasting. The predicted flow discharge results are important for the design of a river regulation or flood protection works, land use planning, and risk mapping (Wilson, 1990). Flood routing is a mathematical procedure, which computes periodic variation on a flood wave and shape of hydrograph in river channels, along the watercourse (Fread, (1981); Linsley et al. (1982)). Accurate estimation of flood characteristics has the advantage to save the costs of an overestimated structures. Also, it reduces damage due to an underestimated flood magnitude in the design procedures (Olivera and Maidment 2000).

The simplification of the flow routing methods in hydrologic and hydraulic models needs consideration for practical application in the actual cases. The hydrologic routing methods are simplified models which can be used at the upstream part of the river basin. Assumptions and simplification made in hydrologic routing methods can be reasonable applied at an upstream area of a river basin. The outputs of these types of models are limited to the average discharge and lag time. Hydrologic routing technique is recognized for a great improvement in the speed and efficiency of computation and less field data requirement for the simulation (Weinmann and Lawrenson, (1979)). This routing technique is not appropriate for rapidly rising hydrographs such 
as dam-break floods. It neglects variable backwater effects due to downstream constrictions, bridges, dams, large tributary inflows, or tidal fluctuations (Mejia and Reed, (2011)). The hydrologic routing method only uses the principle of continuity and a single stage-discharge relationship.

The hydraulic routing method employs the full Saint-Venant Equations, which consist of continuity and momentum equations. Because of an inherent capability, to consider wave shape and channel storage effect in the computation procedures (Bedient and Huber, (1988)), hydraulic routing methods provide more accurate solutions. The continuity equation describes the conservation of mass for a one-dimensional system. Besides, a hydraulic routing method is applied through the use of the river cross-sections and alignment, which provides an opportunity to study floodplains and hydraulic structures on a simulation procedure.

The existing hydrologic routing methods do not perform satisfactorily at the downstream reach of the river, where naturally recognized to complicated patterns. It was the disadvantage of the existing hydrologic routing methods. Whereas hydraulic routing methods need intensive data especially, cross-sections at some critical section which makes their application limited to a certain reach. The combined hydrological and hydraulic routing methods can reduce the data requirement of the hydraulic routing methods. Besides, it can be applied effectively if there are hydrologic catchment modifications due to the construction of any hydraulic structure like a dam.

There are a variety of models which work based on hydrologic and hydraulic routing principles. Among this model, the Soil water assessment tool (SWAT) (Arnold et al. 2011) is the most known model which works on the hydrologic routing method. As a result of the routing method, the model is best for a long-term average hydrological study in a river basin. On the other hand, the hydrodynamic model HEC-RAS (Brunner, 2016) works on a river cross-section and 
alignment, through an application of hydraulic routing. HEC-RAS can solve a river hydrodynamic problem either for the long or short term. The combination of hydrologic and hydraulic routing methods, based on the best applicability, either at an upstream or downstream area of a river basin has several advantages. Precision on a discharge and sediment simulation outputs and consequently a good representation of subprocesses in a simulation are among these merits.

In this research, a combined method of a hydrological and hydraulic routing method was applied to simulate a discharge and sediment. At an upstream part of a river basin, where the slope and other hydrologic characteristics are dominant, a hydrologic routing method was applied. Hydraulics routing method was applied at the middle and downstream parts of a river basin, where river dynamics processes are dominant. Hydraulic routing method at a downstream part includes output from a hydrologic routing on upstream areas, with a loose combination (Argent et al., 2006; Shrestha et al., 2013). The study was applied through a combined application of the SWAT and HEC-RAS model. SWAT model was applied at an upstream part of a basin, based on the hydrologic routing concept. HEC-RAS model was applied at a middle and downstream part of a basin, including output from an upstream part of a basin.

\section{Study area and Modeling approach}

The awash river is located in the central and eastern part of Ethiopia, it flows from the central highlands to the eastern part of Ethiopia. It is the most widely used river in Ethiopia. The study area considers an upstream part of the basin above a Koka Dam (Fig. 1), which is located between latitudes of $8^{\circ} 16^{\prime}$ and $9^{\circ} 18^{\prime} \mathrm{N}$ and longitudes of $37^{\circ} 57^{\prime}$ and $39^{\circ} 17^{\prime}$ E. Ginich highland areas are sources of the river. It flows to a downstream area at afar region, which is one of the regions in eastern Ethiopia. 


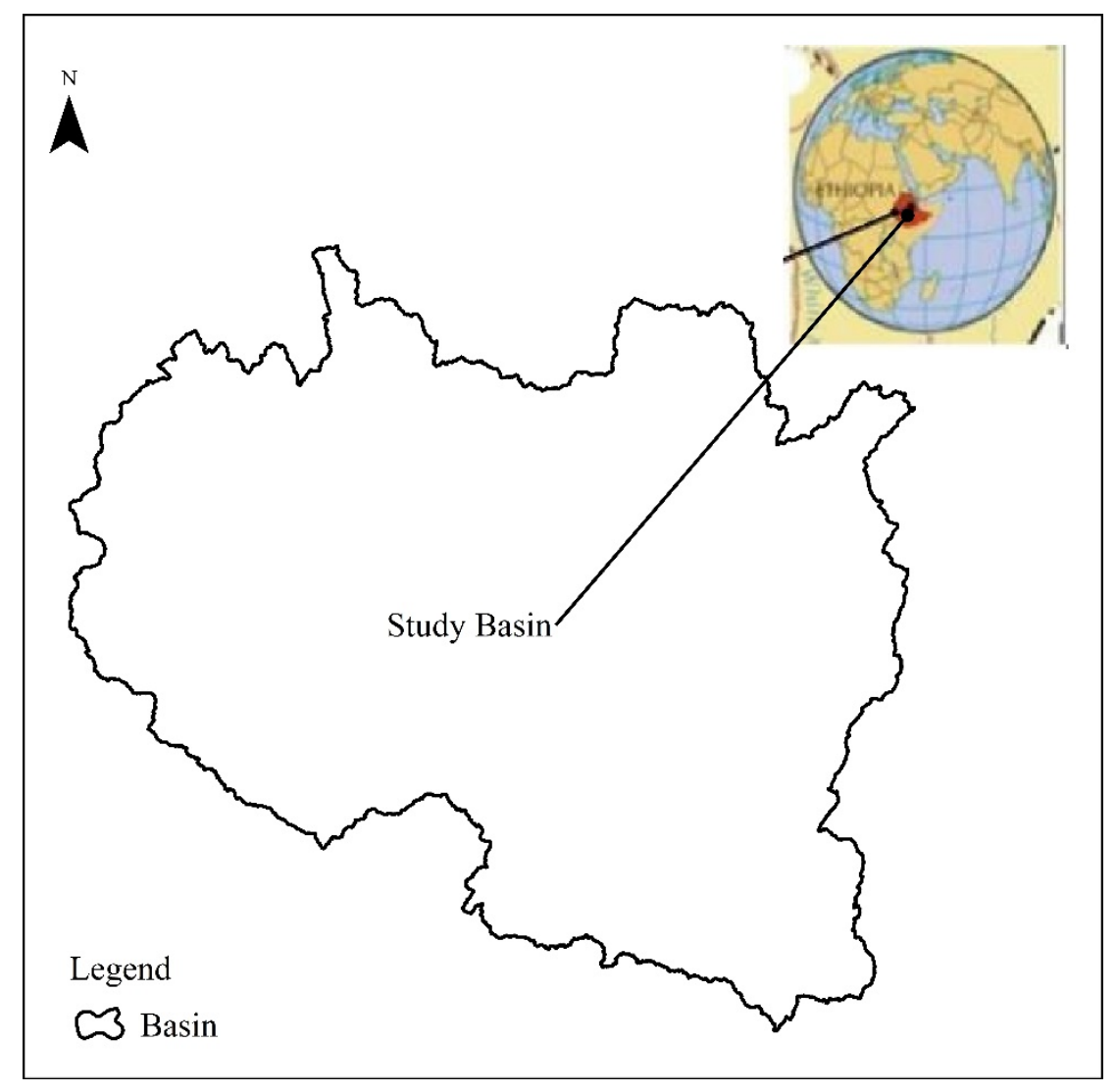

Figure 1 Map of the Awash Basin (upstream of Koka dam)

Simplification and assumptions made on a model development are a major concern during the selection of a model. The method of routing in any model has a significant effect on the output of models. In this research, based on the relative appropriateness of the routing technique to handle a problem, a combined routing method was applied in the Awash River basin. The lumpsum routing methods were applied at an upper part of a river basin, where river dynamics was not the dominant process. Hydraulic routing was carried out at a middle and downstream part of the basin, where an impact of river flow action is dominant. 


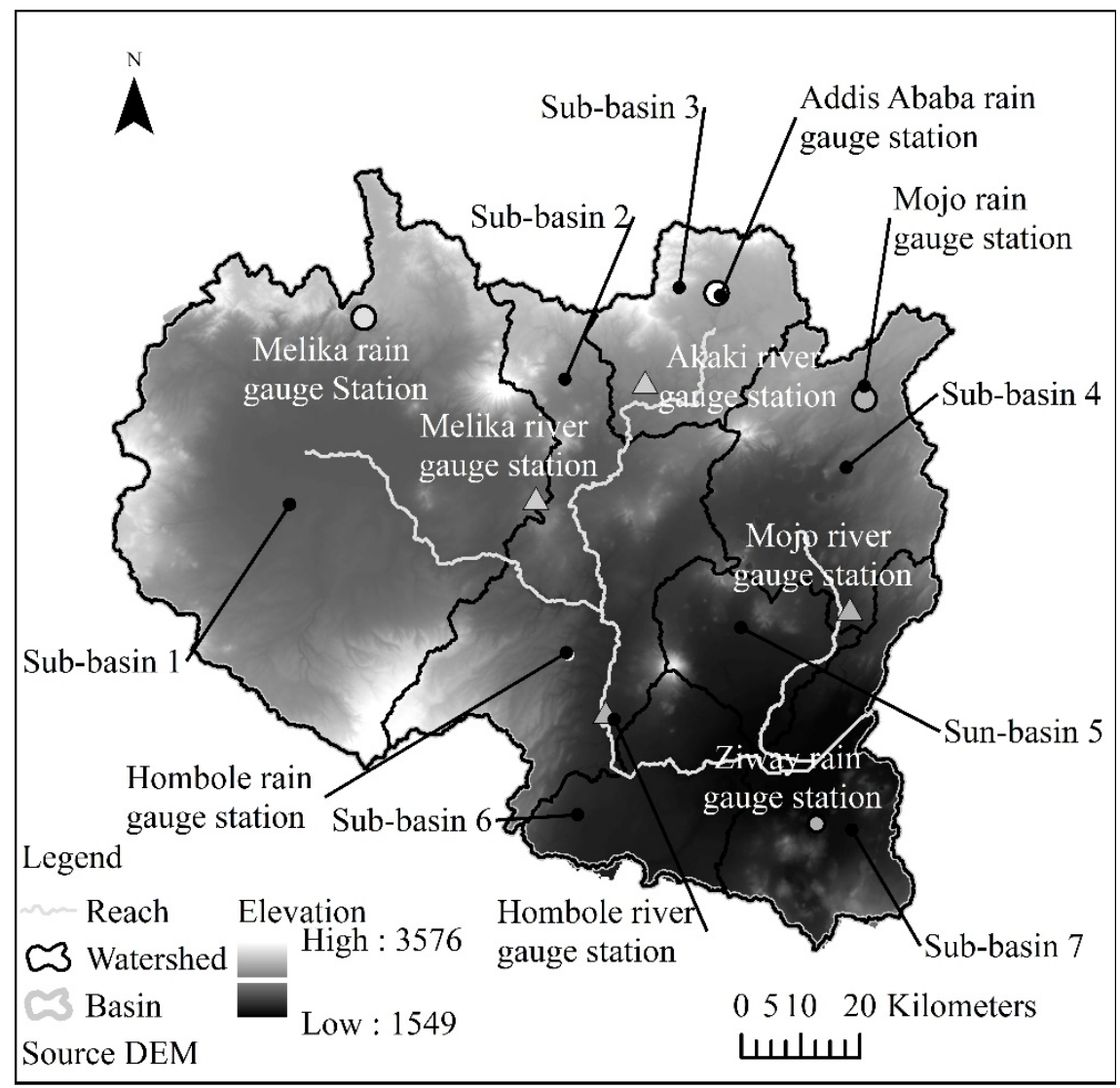

Figure 2 Sub-basins and major river networks in the study area.

The approach in this study has two major steps; the first was an application of a hydrologic routing method, in a selected seven sub-basin as shown in (Fig.2) through an application of the SWAT model. The second step was an application of a hydraulic routing, at a middle and downstream part of a stream, through the HEC-RAS model.

\section{Model description}

A model application needs a good understanding of a model background, assumption, and simplifications made during model development. It helps to solve a system problem more efficiently and accurately. The knowledge about the hydrological processes at upland and lowland areas, concerning the routing methods are important inputs for a good simulation. The selection of 
the models was done based on the above precondition. Model description for each model is discussed in the following sections;

\subsection{SWAT model description}

SWAT model (Arnold et al. 2011; Neitsch et al., 2011)) is the most familiar river basin or watershed model, that can be applied for a study of water quality modeling. The model was developed through a long decade development effort (Gassman et al., 2007; Williams et al., 2008; Arnold et al., 2012). An application has the potential to solve a wide assortment of problems in water resources studies, which make it to be exhaustively applied in any part of the world (Santhi et al., 2001; Cao et al., 2006; Keshta et al., 2009). SWAT is a conceptual model that was developed to run a model within a different spatial range and temporal range (i.e., daily, monthly, and yearly). It assists the prediction and assessment of the impacts of agricultural practices on sediment, water, and agricultural chemicals, on a large ungagged river basin.

SWAT model was able to handle a large complex river basin or watershed, that has varying management conditions, soil, and land cover. A huge scale spatial variability on a landcover, soil, and management condition, in a river basin, was described through the discretization of a catchment into multiple sub-divisions. The discretization has two major steps; the first step was the categorization of a complex topographic catchment into sub-basins, based on a threshold area. The sub-catchments are furthermore, divided into more homogeneous hydrologic response units (HRUs), based on unique groupings of soil and landcover. Simulation outputs, water, nutrient, sediment, and pesticide pollution were initially determined for each HRU, and later it was aggregated at a sub-basin level. Finally, 
these aggregated outputs were routed through hydrological routing techniques to determine the total outputs, for a stream reaches and catchment outlet in a channel network.

The water balance equation, to simulate a hydrologic cycle at a sub-basin:

$$
\mathrm{SW}_{\mathrm{t}}=\mathrm{SW}_{\mathrm{o}}+\sum_{\mathrm{i}=1}^{\mathrm{t}}\left(\mathrm{R}_{\text {day }}-\mathrm{Q}_{\text {surf }}-\mathrm{E}_{\mathrm{a}}-\mathrm{W}_{\text {seep }}-\mathrm{Q}_{\mathrm{gw}}\right)
$$

where $S W_{t}=$ final water content on day $\mathrm{t}(\mathrm{mm}), S W_{0}=$ initial water content on day i $(\mathrm{mm})$, $\mathrm{R}_{\text {day }}=$ precipitation on day $\mathrm{i}(\mathrm{mm}), Q_{\text {surf }} \mathrm{i}=$ surface runoff on day $\mathrm{i}(\mathrm{mm}), E_{a}=$ evapotranspiration on day $\mathrm{i}(\mathrm{mm}), W_{\text {seep }}=$ water entering the vadose zone from the soil profile on day i $(\mathrm{mm})$, and $Q_{g w}=$ groundwater return flow on day i $(\mathrm{mm})$.

Modified Universal Soil Loss Equation (MUSLE) (Williams, 1995) is used to estimate sediment produce from each HRU. This method gives due consideration to major components that significantly affect an actual process. The main factors were surface runoff, peak flow rate, soil erodibility, crop management, erosion control practice factor, and slope length and steepness factors.

$$
\begin{aligned}
\text { sed }=11.8\left(\mathrm{Q}_{\text {surf }} * \mathrm{q}_{\text {peak }} * \text { area }_{\mathrm{hru}}\right)^{0.56} & \\
& *\left(\mathrm{~K}_{\mathrm{USLE}} * \mathrm{C}_{\mathrm{USLE}} * \mathrm{P}_{\mathrm{USLE}} *(\mathrm{LS})_{\mathrm{USLE}} * \mathrm{CFRG}\right)
\end{aligned}
$$

where sed is the sediment yield on a given day (metric tons); $Q_{\text {surf }}$ is surface runoff volume $(\mathrm{mm}) ; q_{p e a k}$ is peak runoff rate $\left(\mathrm{m}^{3} / \mathrm{s}\right)$; area $_{h r u}$ is area of $\mathrm{HRU}(\mathrm{ha}) ; K_{U S L E}$ is the soil erodibility factor $\left(0.013\right.$ metric ton* $m^{2} * h r /\left(m^{3} *\right.$ metric ton $\left.* \mathrm{~cm}\right) ; C_{U S L E}$ is the cover and management factor; $P_{U S L E}$ is the support practice factor; $L S_{U S L E}$ is the topographic factor; and $C F R G$ is the coarse fragment factor. 


\subsection{HEC-RAS model description}

HEC-RAS(Brunner, 2016) is a numerical model, which can solve one-dimensional and twodimensional, steady, and unsteady flows in natural or manmade open channel networks. The model codes were developed by the U.S. Army Corps of Engineers. Implementation of a model requires input data and understanding of a capability of a model to solve an intended problem. HEC-RAS model requires the layout of a channel network, cross-sections, length of reaches, stream junctions, energy loss coefficients, and hydraulic structure information. The model outputs are too many, that depend on a modeling plan, some of them are a flow discharge, water level, velocity, flood area, discharge vs water level, etc. The cross-sections of a river are important inputs on an HEC-RAS model, it should be provided at a maximum of $6 \mathrm{~km}$ range. However, if there are changes in shape, slope, discharge, or roughness in between a given length, more cross-sections are required for an appropriate representation of a system in a modeling process.

Hydrodynamic models require boundary conditions at an upstream and downstream location of a river system, to define the starting water level, for a simulation task. Water level profile computations in an HEC-RAS model, for subcritical flow, are done by moving upstream, but for supercritical flow, the process moves in the opposite direction or downstream. Water level profiles, for a simulation process, were calculated from discharge data at each cross-section. The water-surface profiles can be calculated, for steady and unsteady flows in the HEC-RAS model. One-dimensional energy equation (USACE, 1990) was solved through, a backward standard step method, which was later applied to calculate the watersurface profile, from downstream to upstream. Floodplains management in rivers can be assessed through the use of a steady flow computation system in the model (Reed \& 
Maidment, 1995). Correspondingly, the channel and levees improvement can change the water level profiles in a river system, HEC-RAS can be applied for the evaluation of such changes on river channels.

The integration of an HEC-RAS model with the Geographic Information System (GIS), makes a simulation process more efficient. This process was done through the use of an HECGeoRAS. The integration was made on an improved version of Arc-View extension (AVRAS) in the University of Texas (Maidment \& Djokic, 2000). The GIS system allows extracting a river cross-sectional geometry and alignment, from a digital terrain model or Triangulated Irregular Network (TIN). The water depth and velocity in a river cross-section can be an interpolated results between each cross-section.

Discharge hydrographs in the HEC-RAS model were represented by a sequence of steady flows discharge simulation outputs. The steady system is designed to predicate and simulate a change in a moderate period, that happens on a river profile, as a result of scouring and/or deposition of sand, silt, and clay particles. The inputs required are cross-section and alignment of the river, discharge and, sediment concentration data. It also needs a channel roughness, for calibration of a discharge and changes in boundary conditions. The model computes the water surface profiles and velocities of a flow at a required cross-section along the river reach.

The governing equation in the HEC-RAS model is continuity and momentum equations as any hydrodynamic model.

$\frac{\partial \mathrm{A}}{\partial \mathrm{t}}+\frac{\partial \mathrm{S}}{\partial \mathrm{t}}+\frac{\partial \mathrm{Q}}{\partial \mathrm{x}}-\mathrm{q}_{1}=0$

where $\mathrm{x}=$ distance along the channel, $\mathrm{t}=$ time, $\mathrm{Q}=$ flow, $\mathrm{A}=$ cross sectional area, $\mathrm{S}=$ storage from non-conveying portions of cross section, $q_{1}=$ lateral inflow per unit distance The equations can be re-written for the channel and floodplains 


$$
\begin{gathered}
\frac{\partial \mathrm{Q}_{\mathrm{c}}}{\partial \mathrm{x}_{\mathrm{c}}}+\frac{\partial \mathrm{A}_{\mathrm{c}}}{\partial \mathrm{t}}=\mathrm{q}_{\mathrm{f}} \ldots \ldots \ldots \ldots \ldots \ldots \\
\text { and } \\
\frac{\partial \mathrm{Q}_{\mathrm{f}}}{\partial \mathrm{x}_{\mathrm{f}}}+\frac{\partial \mathrm{A}_{\mathrm{f}}}{\partial \mathrm{t}}+\frac{\partial \mathrm{S}}{\partial \mathrm{t}}=\mathrm{q}_{\mathrm{c}}+\mathrm{q}_{1}
\end{gathered}
$$

where the subscripts $\mathrm{f}$ and $\mathrm{c}$ refer to a floodplain and channel, respectively, and $\mathrm{q}_{1}$ is lateral inflow per unit length of the floodplain, and $\mathrm{q}_{\mathrm{c}}$ and $\mathrm{q}_{\mathrm{f}}$ are the exchange of water between a channel and floodplain.

The momentum equation states the rate of change in momentum is equal to the external force acting on a system. For channels the following case is considered:

$$
\frac{\partial \mathrm{Q}}{\partial \mathrm{t}}+\frac{\partial(\mathrm{VQ})}{\partial \mathrm{x}}+\mathrm{gA}\left(\frac{\partial \mathrm{z}}{\partial \mathrm{x}}+\mathrm{S}_{\mathrm{f}}\right)=0
$$

Where $\mathrm{g}=$ acceleration due to gravity, $\mathrm{S}_{\mathrm{f}}=$ frictional slope, $\mathrm{V}=$ velocity

The above equation can be written with consideration of a floodplain as follows.

$$
\begin{gathered}
\frac{\partial Q_{c}}{\partial \mathrm{t}}+\frac{\partial\left(V_{c} \mathrm{Q}_{c}\right)}{\partial \mathrm{x}_{c}}+\mathrm{gA}_{c}\left(\frac{\partial \mathrm{z}}{\partial \mathrm{x}_{c}}+\mathrm{S}_{\mathrm{fc}}\right)=\mathrm{M}_{f} . \\
\frac{\partial Q_{f}}{\partial \mathrm{t}}+\frac{\partial\left(V_{f} \mathrm{Q}_{f}\right)}{\partial \mathrm{x}_{f}}+\mathrm{gA}_{f}\left(\frac{\partial \mathrm{z}}{\partial \mathrm{x}_{f}}+\mathrm{S}_{\mathrm{ff}}\right)=\mathrm{M}_{c}
\end{gathered}
$$

Where $\mathrm{M}_{\mathrm{c}}$ and $\mathrm{M}_{\mathrm{f}}$ are the momentum fluxes per unit distance exchanged between the channel and the floodplain, respectively.

In a simulation process, to establish the starting water surface profiles, at an end of a river system, boundary conditions are desirable. At an upstream reach of a model, a water level or discharge data are core boundary conditions. Initial water levels are used as a downstream boundary condition. Discharge information is required at each cross-section from upstream to downstream. Cross-sectional data at a maximum of $6 \mathrm{Km}$ distance must be provided. An alignment 
of a river and elevation data are among the basic data required for a simulation process. The discretization of a numerical method was done using the implicit finite difference method.

\section{Model development for the study river basin}

The simulation processes in this research had two major steps; the first task was an application of the SWAT model on an entire basin. Hydrologic routing technique was applied on the subbasins (Fig. 1). HEC-RAS model application, on a middle and downstream part of the river basin, where river dynamics processes are dominant, was a second step. At this step, flow and sediment inputs data were extracted from a previous hydrological routing simulation. Hence, a final simulation considers both hydrologic and hydraulic routing techniques in common.

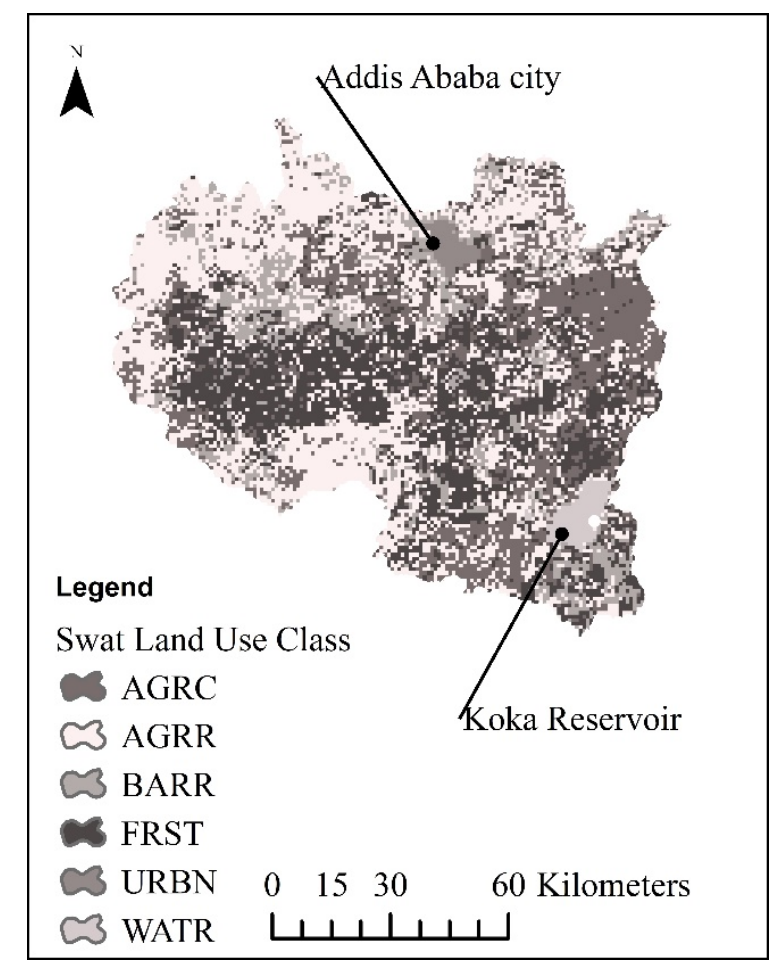

Figure 3 Land use map of upper Awash Basin.

The model development process requires weather data, DEM, Land use, and soil data for the simulation task. The DEMs were collected online from (https://www.asf.alaska.edu $)$ data sources. Land use data were collected from (http://maps.elie.ucl.ac.be/CCI/viewer/download.php) (Fig.3) 
and soil data were from the FAO soil database. Weather data were collected from the Ethiopian metrological agency. Flow discharge data, that were used for calibration and validation of a model, were collected from the Ethiopian Ministry of Water Resources, Energy and Irrigation.

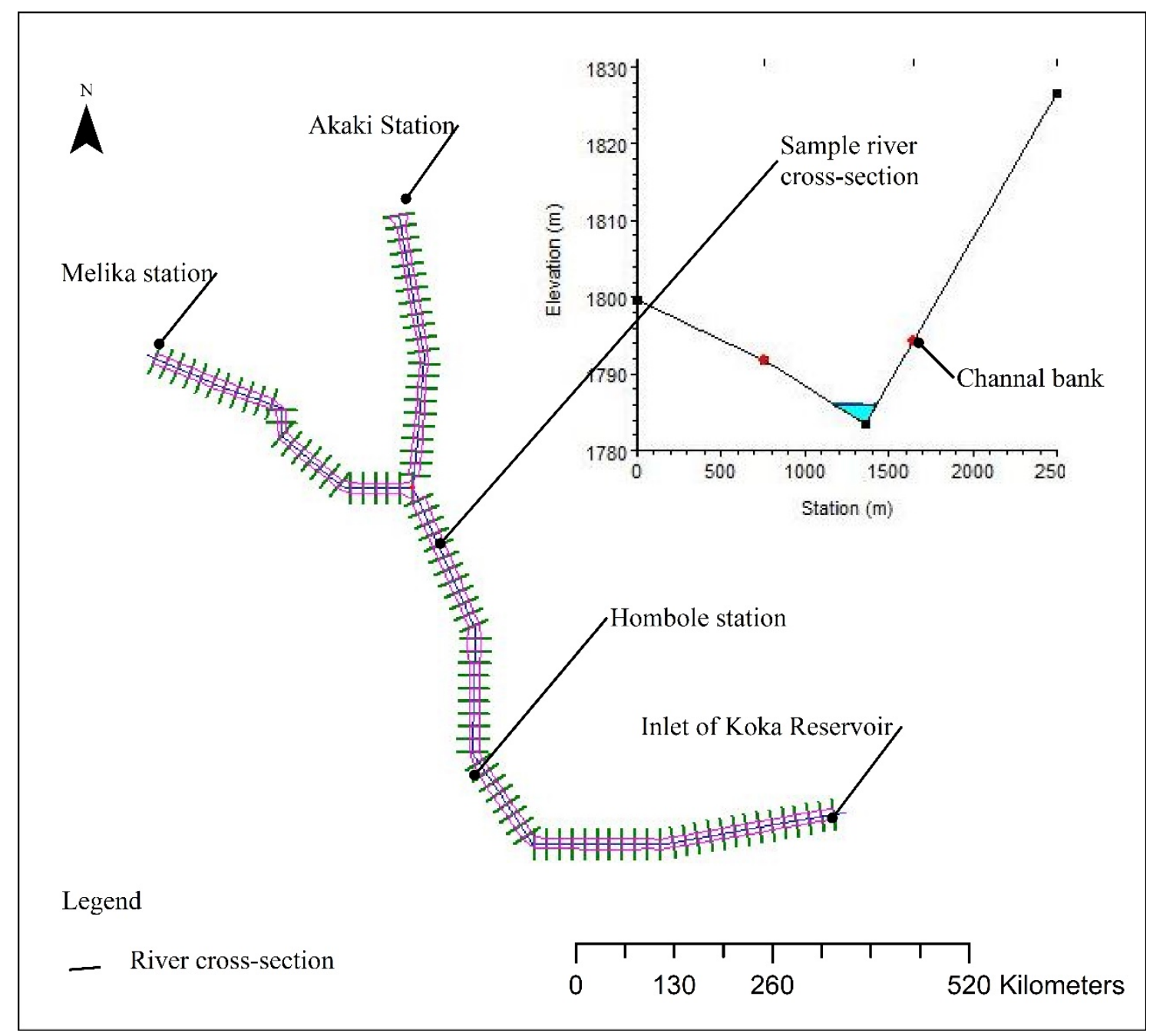

Figure 4 Layout of a combined hydrologic-hydraulic model.

Fig. 4 shows the layout of a system modeling on an HEC-RAS model. The input data, for a model, was extracted from a SWAT model applied on an entire basin at an initial stage. The system was a combination of hydrologic and hydraulic modeling. HEC-RAS model uses the output from a SWAT model, as input to model a flow discharge and sediment dynamics in a basin, using a 
hydraulic routing technique. The additional input, for an HEC-RAS model, such as an alignment and cross-sectional data were extracted from, a Digital Elevation Model (DEM) data of $12.5 \mathrm{~m}$ by $12.5 \mathrm{~m}$ (https://www.asf.alaska.edu). The HEC-GeoRAS tool was used to extract the required information from the DEM.

\section{Model calibration and uncertainty}

\subsection{Model calibration and validation}

Model calibration is a process that entails a modification of certain model parameters, to achieve the best performance of a model, for specific locations and applications. Calibration involves the estimation of various constants and parameter values in a model structure. Similarly, validation is a test of an agreement of prediction and observation events, with the same parameters that are used for calibration. Validation is achieved by running a model, using data covering an alternative period and/or a different location, without making any adjustment to model parameters.

There are manual and automatic methods, that can be used for the calibration and validation of the SWAT model. Automatic calibration can be done through SWAT-CUP tools (Abbaspour, 2015). Manual calibration has the following steps 1) perform trial simulation 2) compare simulated and observed values 3) test the fitness of those values to each other 4) if the values are not close to each other, change a parameter until reasonable values were found. This method is laborintensive, due to many trials were required during calibration processes (Balascio et al., 1998).

\subsubsection{SWAT -CUP}

SUFI-2 algorithm in a SWAT-CUP tool was an optional tool, which can be used for the uncertainty analysis and calibration of a SWAT model (Abbaspour et al., 2007a). It uses the parameter optimization method. Uncertainty predictions of 95\% (95PPU) are used to quantify uncertainty in the outputs, by calculating $2.5 \%$ and $97.5 \%$ levels of the cumulative distribution of 
an output variable. It was done through a Latin hypercube sampling. Performance of the uncertainty/calibration can be evaluated through, P-factor and R-factor. Where P-factor is the percentage of bracketed through the 95PPU band and R-factor is an average width of the band divided by a standard deviation of a corresponding measured variable.

A specific recommendation for the $\mathrm{P}$ and $\mathrm{R}$ values was not fixed but it was suggested that large values are preferable. R-factor of near to one and a P-factor of more than 0.7 can be considered a good value for discharge calibration and validation. For sediment, a larger R-factor a smaller P-factor and could be tolerable. (Abbaspour, 2015).

Table 1 Calibration parameters for the SWAT model

\begin{tabular}{ccc}
\hline Name of parameter & Min. Range & Max. Range \\
\hline CN2.mgt & 0.076713 & 0.103421 \\
ESCO.hru & 0.575959 & 0.827777 \\
SOL_AWC().sol & 0.575959 & 0.81255 \\
ALPHA_BF.gw & -0.630987 & -0.495211
\end{tabular}

The SWAT parameters were tested for the basin for their sensitivity in the overall basin parameters. After many trials based on the sensitivity, the above four parameters in Table 1 were the most important parameters used for calibration and validation.

\subsubsection{Hydrodynamic model calibration}

The bed roughness factor of a river channel network is an important parameter, that is used for the calibration of any hydrodynamic model. The calibration process was carried out by adjustment of the bed roughness factor, based on a reasonable range and channel characteristics. The bed roughness values have two major categories, a main channel and flood plains. It is based 
on the difference in characteristics and plant growth on a channel. Actual values, for a bed roughness, are determined from a discharge measurement and computation through manning's formulas. Also, channel characteristics and previous experience in modeling are important considerations for the estimation of reasonable values. In this research, the bed roughness for the main channel and flood plain was estimated, based on a study of the channel characteristics and investigation of similar trends in previous studies, at different parts of the world for analogous cases (French, 1985; Bedient \& Huber, 2002; Phillips \& Tadayon, 2006). The final values were decided after a certain adjustment on an initial estimated value, to fit observed and simulated events keeping the roughness values within a recommended range.

The Manning's bed roughness was used for the calibration of the daily time-step model. For the main river channel, the range was $0.025-0.045$ and the best fit value was 0.035 . Similarly, for the flood plain areas, the Manning's value range in between $0.045-0.060$, and the best fit value was 0.050 .

\section{Flow Discharge modeling outcome}

The discharge in a river was simulated through an application of a SWAT model by subdividing an entire basin into seven sub-basins (Fig 2). The sub-basin was arranged to apply a loose combination of models at an upstream and downstream part of a basin. The outputs of the SWAT model were provided as input for the HEC-RAS model at selected stations, to integrate hydrologic and hydraulic routing methods on the simulation process. Calibration of a SWAT model was done through an application of a SWAT-CUP, calibration, and validation tools. While, an integrated model was calibrated through the use of manning's coefficients, selected based on literature and expertise from a previous modeling task. 


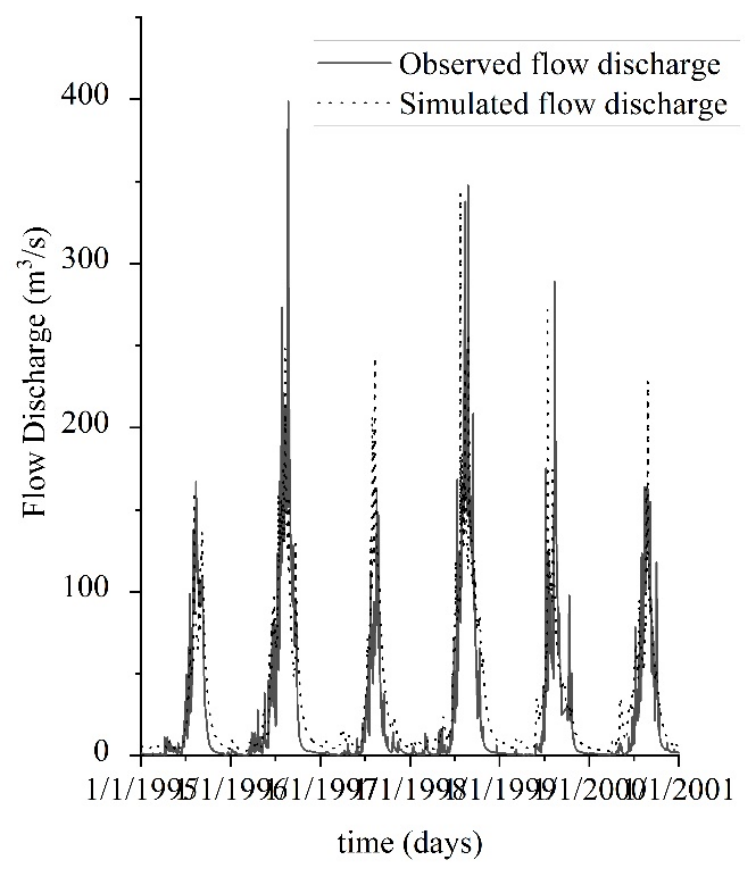

Figure 5 Flow discharge calibration at Melika Kunture station

A SWAT model calibration output was shown in Fig. 5. It indicates that there is a good relationship between an observed and simulated discharge, at a Melika Kunture station. The $\mathrm{R}^{2}$ and NSE, for the calibration process, were 0.72 and 0.7 , respectively. The performance indicators revealed that a model was performing in good condition. Hence, an output of modeling efforts can be used for practical application. The calibration outputs were for the daily flow discharges from $1995-2000$. 


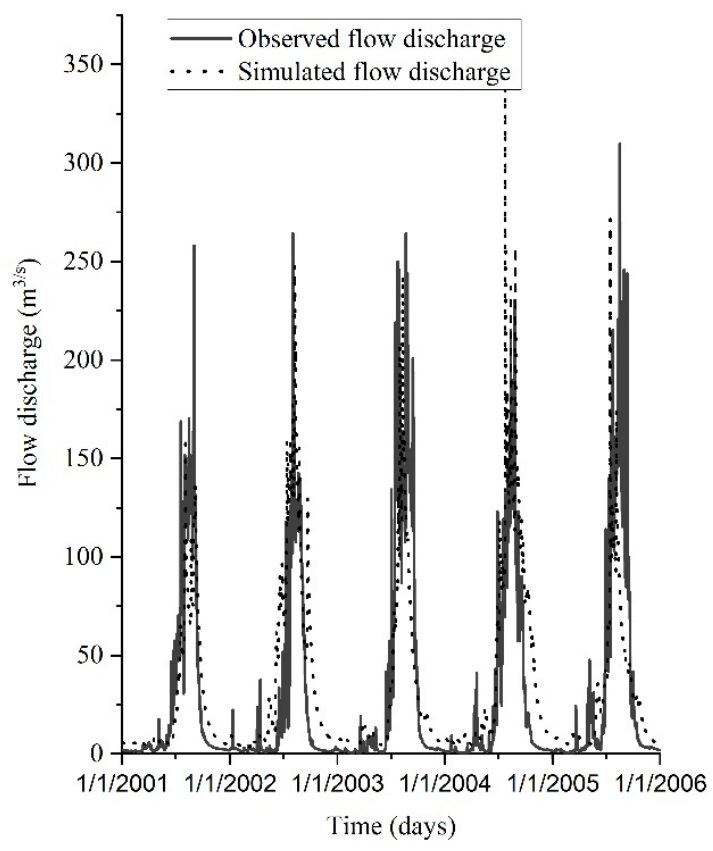

Figure 6 Flow discharge validation at the Melika Kunture station.

After a calibration process was completed, validation was another important instant to evaluate a performance of a model. Therefore, a validation process, for a flow discharge was done, for daily flows, from $2001-2005$. Validation process performance was expressed through the $\mathrm{R}^{2}$ and NSE, which had a value of 0.7 and 0.69 , respectively. These values indicate that model performance was in a good range. Hence, model outputs can be used for the Awash basin management. 


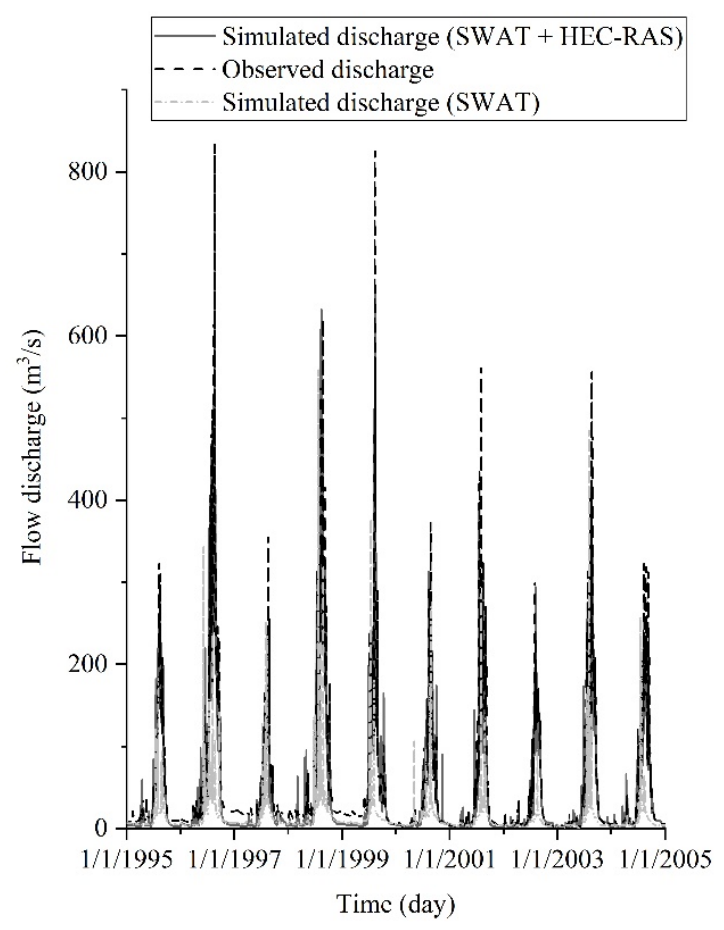

Figure 7 Comparison of observed and simulated discharge at Hombole station.

The simulation process was executed based on the DEM collected in 2003-2004, practical application of DEM data is common, for long-term study, in hydrological modeling. However, for hydrodynamic models, it is not applicable, mainly due to the dynamics in a bed level changes, particularly, for a sediment study. To evaluate the effects of the DEM, on long-term hydrological studies, a simulation was made and the results from a simulation process were shown in Fig. 7. The result indicates the simulated discharge has a good agreement with observed values, for the long-term study too.

The short-term flow discharge result from the SWAT model and a combined SWAT and HEC-RAS was shown in Fig. 8. NSE and $\mathrm{R}^{2}$, for a SWAT model, are 0.6 and 0.65 , respectively. It indicates a good relationship between observed and simulated values. On other hand, a Coupled model of SWAT and HEC-RAS has NSE and $\mathrm{R}^{2}$ values of 0.91 
and 0.89 , respectively, which shows a very good relationship between a simulated and observed value.

The key point from the evaluation of simulation outputs, both models (SWAT and a combined SWAT and HEC-RAS) satisfy performance evaluation requirements. However, when temporal variations come into consideration, a model needs to be categorized into long- and short-term events. Performance indicators were the main consideration, during evaluation processes, in most of the research works. However, in these days, it is clearly understood that, due to the impacts of climate change, hydrologic events are erratic, which requires an advanced model, to predicate a peak or higher discharge values, for an individual incident in addition to an average value. Therefore, a decision on a model performance has to include a simulation horizon, to resolve an intended water resources problem appropriately.

Evaluation of higher or peak flows in a simulation process was one of the considerations in this research. Fig. 8 shows that a SWAT model was not good in simulating those higher values even if the overall performance is in a good range. A SWAT and HEC-RAS coupled model relatively better at simulating those peak flows with very good model performance. This difference in the outputs was an effect of routing methods on application models. It is an output of this research, which provides good results because of a selection of a combined routing method as a hydraulic and hydrologic model. It is one of the improvements in this research that indicate that a coupled model can be applied for both event-based as well as long-term planning. The simulation outputs were shown in Fig. 8, for both SWAT and Coupled of SWAT and HEC-RAS model. 


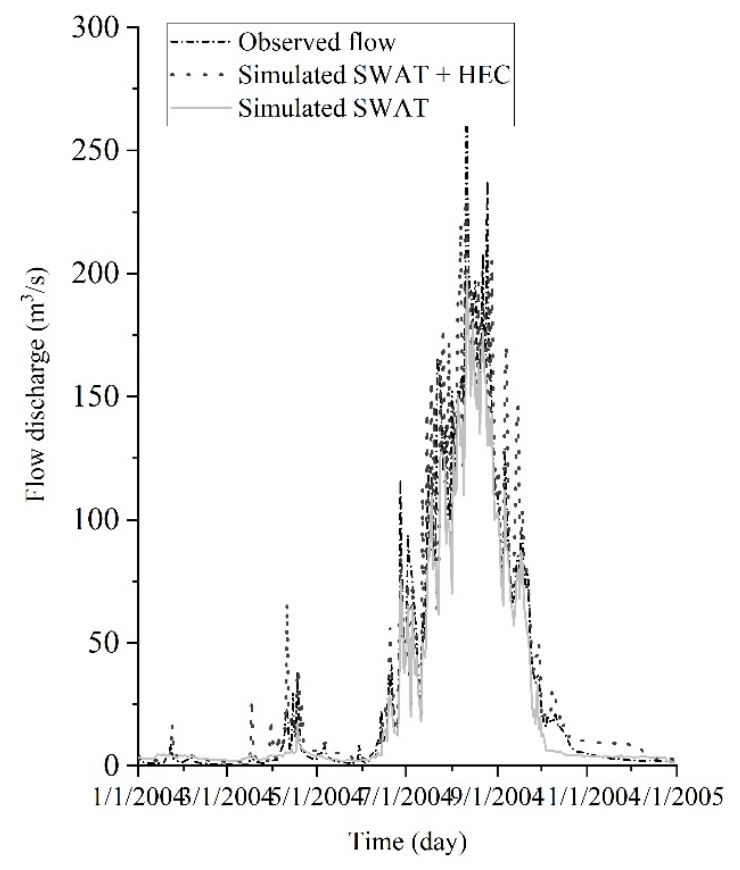

Figure 8 Comparison of discharge simulations based on the DEM data collection period A hybrid model provides an opportunity to evaluate cross-sections of a river at a time where the Digital elevation model (DEM) data were collected. The river dynamics process will change a river cross-section frequently. Therefore, a modeling approach, particularly for sediment modeling with the use of the DEM data, for the long-term, needs serious consideration. The model outputs in Fig. 8 (only for 2004) were provided by considering a data collection period for the DEM data.

Flow discharge predictions are important for the design of hydraulic structures, flood forecasting, reservoir operation, etc. During such cases, cumulative frequencies are important to understand, the probabilistic condition of a flood event. The cumulative frequency analysis for the probability test of a simulated (SWAT and combined SWAT and HEC-RAS) outputs was evaluated with, the $90 \%$ confidence interval ranges of an observed discharge. The result from the evaluation of a cumulative frequency was shown in Fig.10. Outputs on Fig.10 show the 
comparisons of cumulative frequencies of an observed discharge and its $90 \%$ confidence interval, with simulation outputs from the SWAT model alone and coupled model of SWAT and HEC-RAS. The comparisons show, for the coupled model of SWAT and HEC-RAS, that almost all the simulated flow discharges are within the $90 \%$ confidence interval range of measured values. This entails a good agreement between simulated and observed values. Whereas, a Simulation outputs from a SWAT model, most of the simulated values are outside the $90 \%$ confidence interval. The output indicates that there is a poor agreement between simulated and observed values.

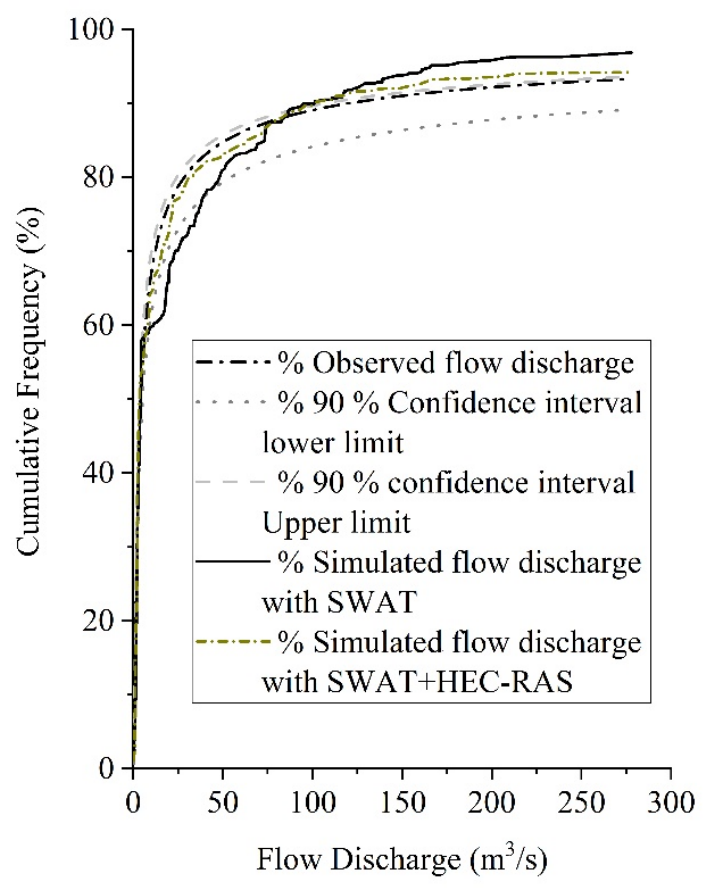

Figure 9 Cumulative frequency distribution for observed and simulated discharge 


\section{Sediment modeling processes}

Sediment modeling is a complex process due to an interaction of a process with flowing water and the difficulty of a direct measurement of the process from the field. Sediment concentrations can be directly measured, by taking samples, from a flow discharge in rivers, but the sediment loads need further analysis, to convert measured sediment concentrations to sediment loads. Measured suspended sediment concentration can be converted to sediment loads using an equation given below.

$$
Q_{s}=Q_{w} * C * K
$$

where; $Q_{s}$ is the sediment loads in tons/day, $Q_{w}$ is discharg $\left(\mathrm{m}^{3} / \mathrm{s}\right), C$ is sediment concentration $(\mathrm{mg} / \mathrm{l})$ and $K$ is unit conversion constant 0.0864

The main challenge in sediment modeling, it is difficult to obtain continuous daily or subdaily measured concentration data at most of the gauging stations. In such case, the analytic techniques are applied, to estimate parameters based on statistical approach on available data (intermittently collected for a long time) sets, which can be applied using Eqn. 14 ( $\mathrm{a}$ and $\mathrm{b}$ are statistical driven parameters).

$$
Q_{s}=a Q_{w}{ }^{b}
$$

where $Q_{s}$ is sediment loads (ton/day), $Q_{w}$ is flow discharge $\left(\mathrm{m}^{3} / \mathrm{s}\right)$ and a $\&$ b are coefficients that are derived from statistical regression analysis.

The sediment loads that are computed by the eqn. 14 had been observed in underestimating the sediment loads, from a given station (Jones et al., 1981; Ferguson, 1986; Walling and Webb, 1988; Asselman, 2000). Many bias correction methods were recommended by different researchers, to improve an underestimation effect (Duan, 1983, Ferguson, 1986; de Vries and Klavers, 1994; Phillips et al., 1999; Holtschlag, 2001). On the other hand, if historical reservoir 
sedimentation data is available at the station, rather than using these bias correction methods a historical reservoir sedimentation data was preferable, because of a representation of a physical event in a river basin.

In this research, there are few suspended sediment data, from three stations Akaki, Melika Kunture, and Hombole station was available. A regression model was developed for each station, from a sample suspended sediment concentration. Besides, to improve the underestimation effect of those regression models, long-term sediment historical data, at Koka Reservoir was used during a calibration process.

Sediment transport computation in an HEC-RAS model can be solved through an application of a different transport function, that was developed by; Meyer-Peter and Muller (1984), Toffaleti (1968), Ackers and White (1993), Engelund and Hansen (1967), Wilcock and Crowe (2003), Laursen (1963), and Yang (1984). Previous experience on a model application and an understanding of background conditions on transport functions are important conditions, for the selection of an appropriate transport function. The best choice of a transport function will be based on a good agreement of observed and simulated sediment data. Hydraulic parameters are a major requirement for a selected sediment transport module. Therefore, HEC-RAS computes the hydraulic parameters each time before a sediment computation or updating the crosssection because of the sediment transport progression. HEC-RAS couple's sediment transport computations either with quasi-unsteady or unsteady flow hydraulics computations that are available on a model.

\subsection{Sediment modeling outcome}

Evaluation of the sediment result was shown in two categories, as a sediment concentration and sediment loads. Direct outputs of a sediment concentration were evaluated as shown in Fig. 
11 and 12, for SWAT and coupled model, respectively. A reach-specific regression model (sediment rating curves) was developed, for each station, to convert a sediment concentration into the sediment loads. The sediment loads computed, from a regression model were calibrated using long-term sediment deposition data in a Koka Reservoir. The comparisons of model outputs in SWAT, coupled model of SWAT and HEC-RAS, and a regression model were shown Fig. 12.

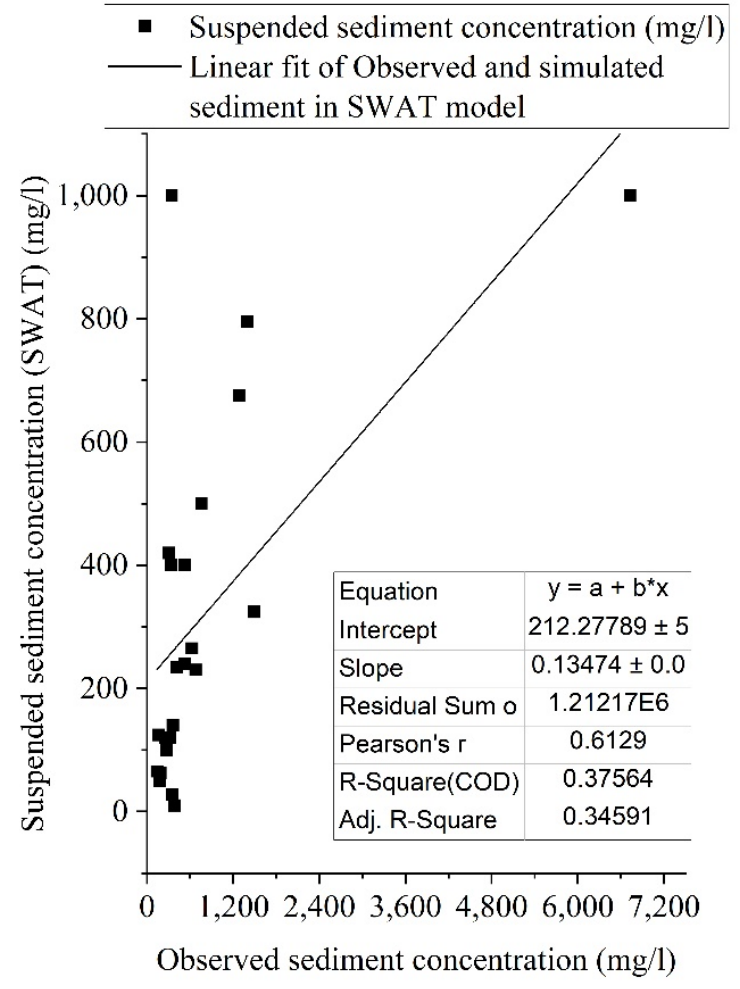

Figure 10 Sediment concentration evaluation on SWAT model.

The sediment concentration evaluation for the observed and simulated event, from the SWAT model, was shown in Fig. 10. The model performance was shown by the $\mathrm{R}^{2}$ value of 0.37 , which indicates that the relationship between an observed and simulated sediment concentration was poor. Therefore, this result provides a sediment loads computation from this simulation that cannot be considered for practical application, for daily analysis. 


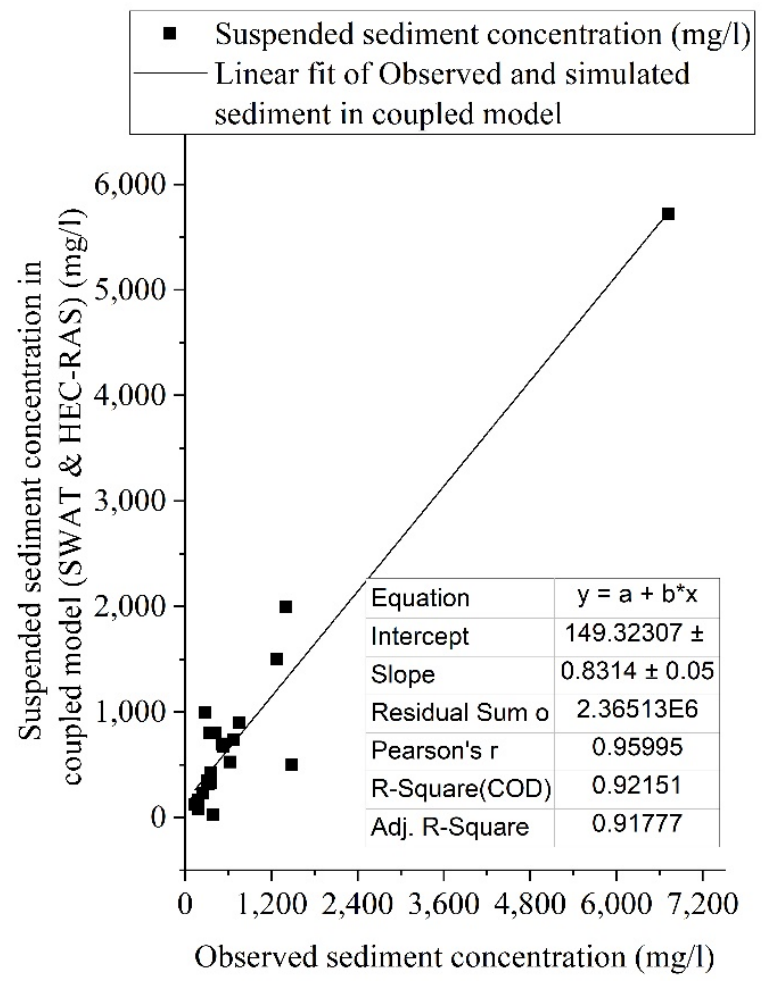

Figure 11 Observed Vs simulated suspended sediment concentration on a coupled model Sediment concentration output from a coupled model (SWAT and HEC) was shown in Fig. 11. The graph shows that there is a good correlation between an observed and simulated suspended sediment concentration in a coupled model. The model performance was shown by an $\mathrm{R}^{2}$ value of 0.92 . This result is an important achievement, for the evaluation of a model on the computation of sediment load. Even if a coupled model can provide, sediment loads as output from a modeling process, practical there is no direct measurement of sediment loads as observed data. A regression model was developed from an observed sample sediment concentration and discharge data. This model was used for the conversion of flow data to sediment loads, based on statistical parameters. Therefore, the conversion of a measured suspended sediment concentration to sediment loads has a certain effect on a comparison of the sediment between observed and simulated data. 


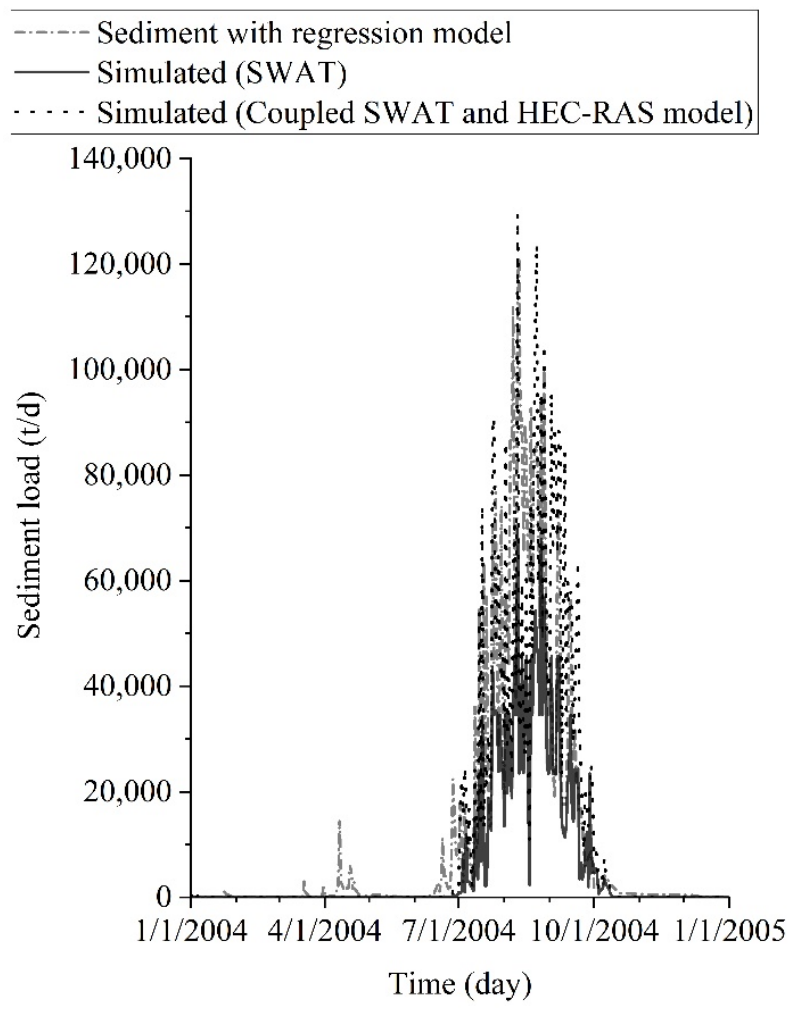

Figure 12 Sediment loads comparison at Hombole station

Sediment loads comparison from the three models, a SWAT, a coupled model of SWAT and HEC-RAS, and a Regression model was shown in Fig. 12. The output from the SWAT model shows that a model is not good at simulating high sediment loads. However, for average sediment loads, a SWAT model can simulate the process. The regression model was developed from sample sediment concentration data and was calibrated by reservoir deposition data. Therefore, relatively it represents an actual process in a basin. A coupled model, SWAT, and HEC-RAS are relatively good in modeling both a high and low sediment concentration.

\section{Conclusion and Recommendation}

Discharge and sediment prediction, mostly depend on a method of routing. Hence, a model selection process should have to give proper consideration for a routing technique. A combined 
routing method, relatively gives a better consideration for all the subprocess, than an individual routing method. The hydrologic routing method in an upstream part of a basin gives better consideration for hydrologic processes in an upstream part of the river basin. Whereas, hydraulic routing at middle and downstream parts of a river basin gives significant consideration for river dynamics processes in a river.

The combined routing method was able to model the peak discharges in a river basin relatively in a more accurate way. It is known that these days, due to the climate change impacts, the rainfall pattern is erratic and difficult to predict exactly. Consequently, the runoff from the rainfall requires advanced techniques to be forecasted reasonably. Therefore, a combined modeling approach is important for flood management and design works in a river basin.

Sediment modeling is complex by nature, which needs a combined knowledge from a different modeling approach. Evaluation of sediment modeling through an application of combined models such as regression models, SWAT, and a combined HEC-RAS and SWAT were among the options, for a practical application. The approach helps to understand sediment transport in detail and to predict a sediment load with good accuracy. An approach like this research can be an alternative for sediment modeling in a river basin.

\section{Acknowledgments}

The author acknowledges the Metrological Agency and Ministry of Water Resources, Energy and Irrigation of Ethiopia, for cooperation on data collection work. 


\section{References}

Abbaspour, K.C. (2015). SWAT-CUP: SWAT calibration and uncertainty programs user manual. Eawag; Swiss Federal institute of Aquatic Science and Technology, Dübendorf, Switzerland.

Abbaspour, K. C., Yang, J., Maximov, I., Siber, R., Bogner, K., Mieleitner, J., ... \& Srinivasan, R. (2007). Modelling hydrology and water quality in the pre-alpine/alpine Thur watershed using SWAT. Journal of hydrology, 333(2-4), 413-430.

Ackers, P., \& White, W. (1993). Sediment transport in open channels: Ackers and White update. Technical note. Proceedings of the Institution of Civil Engineers-Water Maritime and Energy, 101(4), 247-249.

Argent, R. M., Voinov, A., Maxwell, T., Cuddy, S. M., Rahman, J. M., Seaton, S., ... \& Braddock, R. D. (2006). Comparing modelling frameworks-a workshop approach. Environmental Modelling \& Software, 21(7), 895-910.

Arnold, J. G., Kiniry, J. R., Srinivasan, R., Williams, J. R., Haney, E. B., \& Neitsch, S. L. (2011). Soil and Water Assessment Tool input/output file documentation: Version 2009. Texas Water Resources Institute Technical Report, 365.

Arnold, J. G., Moriasi, D. N., Gassman, P. W., Abbaspour, K. C., White, M. J., Srinivasan, R., ... \& Kannan, N. (2012). SWAT: Model use, calibration, and validation. Transactions of the ASABE, 55(4), 1491-1508.

Asselman, N. E. M. (2000). Fitting and interpretation of sediment rating curves. Journal of Hydrology, 234(3-4), 228-248. 
Balascio, C. C., Palmeri, D. J., \& Gao, H. (1998). Use of a genetic algorithm and multiobjective programming for calibration of a hydrologic model. Transactions of the ASAE, 41(3), 615.

Bedient, P.B. and Huber, W.C., 2002. Hydrology and Floodplain Analysis, 3rd Ed. PrenticeHall Publishing Co., Upper Saddle River, 763 pp

Bedient, P.B., and Huber, W.C. (1988). Hydrology and floodplain analysis, Addison Wesley. Reading, Mass.

Brunner, G. W. (2016). HEC-RAS river analysis system 2D modeling user's manual. US Army Corps of Engineers-Hydrologic Engineering Center, 1-171.

Cao, W., Bowden, W. B., Davie, T., \& Fenemor, A. (2006). Multi-variable and multi-site calibration and validation of SWAT in a large mountainous catchment with high spatial variability. Hydrological Processes: An International Journal, 20(5), 1057-1073.

De Vries, A., \& Klavers, H. C. (1994). Riverine fluxes of pollutants: monitoring strategy first, calculation methods second. European Water Management, 4(2), 12-17.

Duan, N. (1983). Smearing estimate: a nonparametric retransformation method. Journal of the American Statistical Association, 78(383), 605-610.

Engelund, F., \& Hansen, E. (1967). A monograph on sediment transport. Technisk Forlag, Copenhagen, Denmark.

Ferguson, R. I. (1986). River loads underestimated by rating curves. Water resources research, 22(1), 74-76.

Fread, D. L. (1981). Flood routing: a synopsis of past, present, and future capability. VP Singh, $521-542$.

French, R. (1985). Open-channel hydraulics. New York: McGraw-Hill. 
Gassman, P. W., Reyes, M. R., Green, C. H., \& Arnold, J. G. (2007). The soil and water assessment tool: historical development, applications, and future research directions. Transactions of the ASABE, 50(4), 1211-1250

Holtschlag, D. J. (2001). Optimal estimation of suspended-sediment concentrations in streams. Hydrological processes, 15(7), 1133-1155.

Jones, K. R., Berney, O., Carr, D. P., \& Barrett, E. C. (1981). Arid zone hydrology for agricultural development.

Keshta, N., Elshorbagy, A., \& Carey, S. (2009). A generic system dynamics model for simulating and evaluating the hydrological performance of reconstructed watersheds. Hydrology and Earth System Sciences, 13(6), 865-881.

Laursen, E. M. (1963). An analysis of relief bridge scour. Journal of the Hydraulics Division, 89(3), 93-118.

Linsley, R. K., \& Kohler, M. A. Paulhus, JLH. 1982. Hydrology for Engineers.

Maidment, D. R. (1993). Handbook of hydrology (Vol. 9780070, p. 397323). New York: McGraw-Hill.

Maidment, D. R., \& Djokic, D. (Eds.). (2000). Hydrologic and hydraulic modeling support: with geographic information systems. ESRI, Inc.

Mejia, A. I., \& Reed, S. M. (2011). Evaluating the effects of parameterized cross section shapes and simplified routing with a coupled distributed hydrologic and hydraulic model. Journal of Hydrology, 409(1-2), 512-524.

Meyer-Peter, E., \& Muller, R. (1984). Formulas for bed load transport. Proceedings of 2nd meeting of the International Association for Hydraulic Structures Research, Delft, (pp. 3964). 
Moriasi, D. N., Arnold, J. G., Van Liew, M. W., Bingner, R. L., Harmel, R. D., \& Veith, T. L. (2007). Model evaluation guidelines for systematic quantification of accuracy in watershed simulations. Transactions of the ASABE, 50(3), 885-900.

Neitsch, S. L., Arnold, J. G., Kiniry, J. R., \& Williams, J. R. (2011). Soil and water assessment tool theoretical documentation version 2009. Texas Water Resources Institute.

Olivera F, Maidment DR (2000) GIS tools for HMS modeling support. In: Maidment DR, Djokic D (eds) Hydrologic and hydraulic modeling support with geographic information systems. Environmental Systems Research Institute Press, USA, pp 85-112

Phillips, J. M., Webb, B. W., Walling, D. E., \& Leeks, G. J. L. (1999). Estimating the suspended sediment loads of rivers in the LOIS study area using infrequent samples. Hydrological processes, 13(7), 1035-1050.

Phillips, J. V., \& Tadayon, S. (2006). Selection of Manning's roughness coefficient for natural and constructed vegetated and non-vegetated channels, and vegetation maintenance plan guidelines for vegetated channels in Central Arizona. Washington, DC: US Department of the Interior, US Geological Survey.

Reed, S. M., \& Maidment, D. R. (1995). A GIS procedure for merging NEXRAD precipitation data and digital elevation models to determine rainfall-runoff modeling parameters. Center for Research in Water Resources Report 95-3, University of Texas at Austin.

Santhi, C., Arnold, J. G., Williams, J. R., Dugas, W. A., Srinivasan, R., \& Hauck, L. M. (2001). Validation of the swat model on a large rwer basin with point and nonpoint sources 1. JAWRA Journal of the American Water Resources Association, 37(5), 1169-1188.

Schuol, J., \& Abbaspour, K. C. (2006). Calibration and uncertainty issues of a hydrological model (SWAT) applied to West Africa. Advances in geosciences, 9, 137-143. 
Shrestha, N. K., Leta, O. T., De Fraine, B., Van Griensven, A., \& Bauwens, W. (2013). OpenMI-based integrated sediment transport modelling of the river Zenne, Belgium. Environmental Modelling \& Software, 47, 193-206.

Toffaleti, F. B. (1968). A Procedure for Computation of the Total River Sand Discharge and Detailed Distribution, Bed to Surface (No. TR-5). Committee on channel stabilization (army).

U.S. Army Corps of Engineers (USACE, 2001): The Columbia River system inside story.

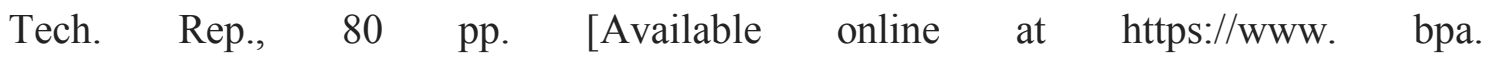
gov/power/pg/columbia_river_inside_story.pdf.].

U.S. Army Corps of Engineers (USACE) (1990). Hydraulics design of spillways. Engineering Manual EM 1110-2-1603, Washington, DC.

Van Liew, M. W., Arnold, J. G., \& Bosch, D. D. (2005). Problems and potential of autocalibrating a hydrologic model. Transactions of the ASAE, 48(3), 1025-1040.

Walling, D. E. (1988). The reliability of rating curve estimates of suspended sediment yield: some further comments. In Symposium on Sediment Budgets, Porto Alegre, Brazil, 1988.

Wilcock, P. R., \& Crowe, J. C. (2003). Surface-based transport model for mixed-size sediment. Journal of Hydraulic Engineering, 129(2), 120-128.

Williams, J. R., Arnold, J. G., Kiniry, J. R., Gassman, P. W., \& Green, C. H. (2008). History of model development at Temple, Texas. Hydrological sciences journal, 53(5), 948-960.

Williams, J. R., \& Singh, V. P. (1995). Computer models of watershed hydrology. chap. The EPIC Model, Water Resources Publications, Highlands Ranch, CO, 909-1000.

WILSON EM (1990) Engineering Hydrology. MacMillan, Hong Kong, China. 
Yang, C. T. (1984). Unit stream power equation for gravel. Journal of Hydraulic Engineering, 110(12), 1783-1797.

\section{Highlights}

- Combined hydrologic and hydraulic routing technique to improve estimation of the discharge and sediment flow.

- Enhancement of the drawbacks of the hydrologic routing methods through a combined approach with hydraulic routing.

- Regression models, SWAT and HEC-RAS application to predicate suspended sediment.

- Application of GIS integrated with 1-D numerical models for discharge and sediment perdiction. 